\title{
Identification and detection of salmonella risk assessment from frozen buffalo meat exported from India
}

\begin{abstract}
Salmonella found in worldwide in cattle and buffalo meat when even it is in frozen condition and even considered among the most important animal related zoonotic disease. Salmonella is a leading cause of foodborne illness. In this paper the focus given to, whether the frozen buffalo meat contain Salmonella or absent in India when it exported to other countries and the sanitary level in abattoir during practicing food safety conditions are up to the mark or not. In the present investigation 56 frozen buffalo meat samples from different cuts like offals, silverside, knuckle, ramstick, tenderline, stripline, topside, thick flam, blade, shoulder, neck etc tested from slaughter houses. The samples were transported to the laboratory where they were examined bacteriologically for determination of their sanitary status. Among the data of 56 samples it is observed that 12 samples are exhibiting absent or negative for Salmonella and 44 samples found positive for Salmonella. The presence of invasiveness and enterotoxicity of Salmonella in frozen buffalo meat showed their ability to cause systemic infections and which may appear to be threat to the public and a health concern. The public health hazards of these microorganisms as well as the recommended measures to improve sanitary quality status of frozen buffalo meat here is discussed.
\end{abstract}

Keywords: salmonella, frozen buffalo meat, zoonotic disease, serotyping, foodborne illness
Volume 2 Issue 2 - 2016

\author{
Ujjal Sen, Anil Mahadeo Garode \\ Department of Microbiology, Kalinga University, India
}

Correspondence: Ujjal Sen, Department of Microbiology, Kalinga University, Raipur, Chattishgarh, India, Tel +919871061902, Email ujjal_sen@hotmail.com

Received: March 30, 2016 | Published: April 19, 2016
Keywords: salmonella, frozen buffalo meat, zoonotic disease, serotyping, foodborne illness

Abbreviations: RVM, rappaport-vassiliadis medium; HE, hektoen enteric; XLD, xylose lysine deoxycholate; BS, bismuth sulphite; BGA, brilliant green agar; AABP, American association of bovine practitioners; AMI, American meat institute

\section{Introduction}

Food borne diseases caused by Salmonella from frozen buffalo meat represent an important public health problem worldwide. Developed and undeveloped countries are struggling hard to fight with Salmonella infections. In United States, an estimated 1.4million cases of salmonellosis is thought to occur annually, of which about 200,000 cases are reported to the CDC. ${ }^{1}$ Salmonellosis is a zonotic disease causing by serious invasive infection in human. Salmonellosis starts from fever and meat of affected animal unfit for human consumption. Most infected persons develop diarrhoea, fever, and abdominal cramps 6 to $72 \mathrm{~h}$ after infection. The illness usually lasts 4 to 7 days. However, too many people continue to get sick and die from eating contaminated frozen buffalo meat. ${ }^{2}$ In Egypt, Salmonella typhimurium was recovered with an incidence ranging from $8.4 \%$ $19.0 \%$ from calves. ${ }^{3}$

Ionizing radiation is able to inactivate food borne pathogens on a variety of food products and can serve as a final critical control point to ensure the microbiological safety of foods. ${ }^{4}$
There are only few reports of incidence of Salmonella from frozen buffalo meat and offals, so, the recent study was undertaken with the aim to isolate and identify Salmonella from frozen buffalo meat and offals from slaughter houses practicing safe and hygienic packaging of frozen buffalo meat in India. The recovered Salmonella isolates were subjected to biochemical characterization.

\section{Salmonella morphology}

Salmonella comes under the family Enterobacteriaceae. They are facultatively anaerobic, fermentative, gram negative, non-acid fast, non-spore forming rods (typically $1-5 \mu \mathrm{m}$ by $1-3 \mu \mathrm{m}$ ) and are generally motile with peritrichous flagella. Growth has been recorded from temperatures just above $5^{\circ} \mathrm{C}$ up to $47^{\circ} \mathrm{C}$ with an optimum at $37^{\circ} \mathrm{C} .5$

\section{Materials and methods}

56 various cuts of Frozen Buffalo meat samples investigated in this study were collected everyday from different slaughter houses of different cut like offals, silverside, knuckle, ramstick, tenderline, stripline, topside, thickflam, blade, shoulder, neck etc and transferred in sterile food bags and analyzed on each day when collected.

\section{Preparation of samples}

a) After $25 \mathrm{gm}$ frozen buffalo meat samples weighed in sterile petridishes, they were homogenized in a blender containing sterile dilution $225 \mathrm{~mL}$ of $0.1 \%$ peptone water under the aseptic condition. The above mentioned method consider as pre-enrichment method and incubated at $37^{\circ} \mathrm{C}$ for 24 hours. ${ }^{6}$

b) Enrichment onto Rappaport-Vassiliadis Medium or Selenite- 
Cystein Broth by transferring $1 \mathrm{~mL}$ pre-enriched broth to $10 \mathrm{~mL}$ above RVM or SCM broth and incubated at $42^{\circ} \mathrm{C}$ for 24 hours or at $40^{\circ} \mathrm{C}$ for 48 hours. ${ }^{7}$

c) Isolation of Salmonella - Plated out the medias Xylose-LysineDeoxycholate Agar, Bismuth sulphite Agar, Hektoen Enteric Agar and Brilliant Green Agar. Prepare BSA plates the day before streaking and store in dark at room temperature until streaked. All the agar plates streaked after enrichment and incubated at $37^{\circ} \mathrm{C}$ for 24 hours. ${ }^{8}$

\section{Identification of salmonella isolates}

i. Hektoen Enteric Agar (HE agar) - Blue-green to blue colonies with or without black centers. Many cultures of Salmonella may produce colonies with large, glossy black centers or may appear as almost completely black colonies.

ii. Xylose Lysine Deoxycholate Agar (XLD Agar) - Pink colonies with or without black centers. Many cultures of Salmonella may produce colonies with large, glossy black centers or may appear as almost completely black colonies.

iii. Bismuth Sulphite Agar (BS agar) - Brown, gray or black colonies. Sometime they have metallic sheen. Surrounding medium is usually brown at first but may turn black in time with increased incubation, producing the so-called hallo effect.

iv. Brilliant Green Agar (BGA Agar) - Pinkish white-orange colonies with surrounding media pink.

All the above plates are incubated at $37^{\circ} \mathrm{C}$ for 24 hours ${ }^{8}$ (Figure 1).

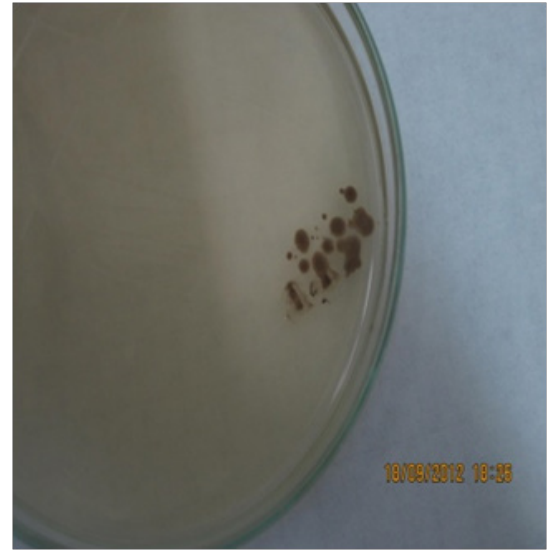

A. Greyish black color colony on BSA.

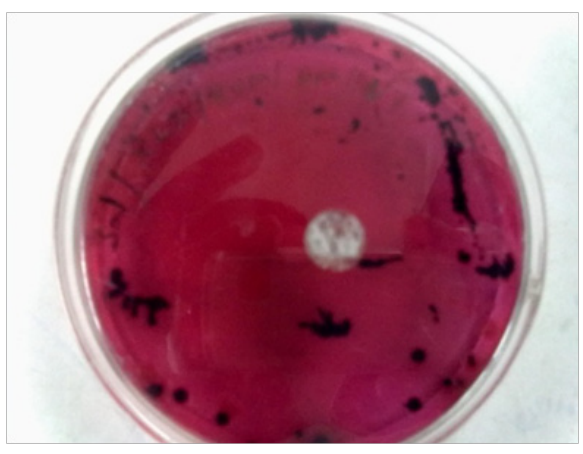

A. Black centered colony on XLD.

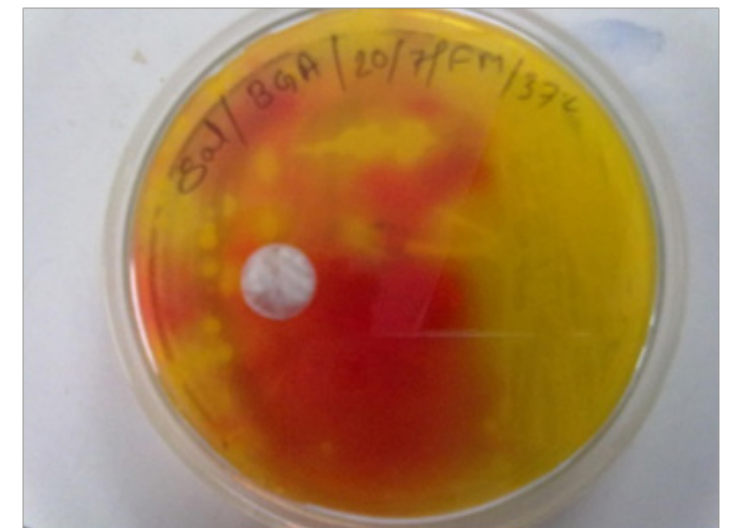

B. Phenol Red colonies on BGA.

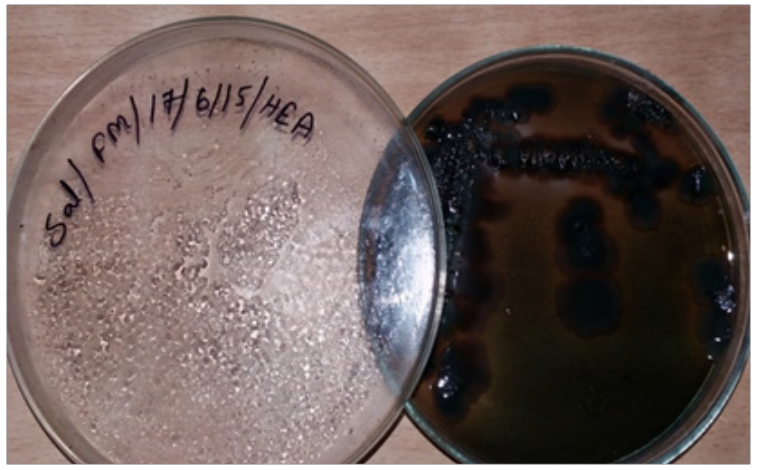

C. Black centered colonies on HEA.

Figure I Salmonella colonies.

\section{Biochemical and serological tests}

There are few biochemical tests which confirmed the presence of above colonies of Salmonellae species. Salmonella on triple sugar iron agar produces hydrogen peroxide and blackening at the butt and slant. Hence $\mathrm{H}_{2} \mathrm{~S}$ positive and also form yellow butt on TSI which means produces acid. Other biochemical reactions like urease negative (no color changed), Indole test negative (Yellow color at surface), VogesProskauer test negative (No color change), Methyl Red Test Positive (Diffuse Red color), Simmon Citrate Negative (No growth no color change or green in appearance). ${ }^{8}$

Serotypically classification of these organisms by antigenic analysis is based on the original work of Kauffmann and White and is often referred to as Kauffmann-White Scheme. Here Somatic and Flagellar antigens are used. Somatic antigens are designed as $\mathrm{O}$ antigens, Flagellar antigen designed as $\mathrm{H}$ antigens and Capsular antigen designed as $\mathrm{K}$ antigens. $\mathrm{K}$ antigen lie at the periphery of the cell and prevent access of anti-O agglutinins (antibodies) to their homologous somatic antigens. The $\mathrm{K}$ antigens differ from ordinary $\mathrm{O}$ antigens is being destroyed by heating for $1 \mathrm{~h}$ at $60^{\circ} \mathrm{C}$ and by dilute acids and phenol. Using $\mathrm{H}, \mathrm{O}, \mathrm{K}$ antigens determined Salmonella species possess it's own genetical determined specificity. Most of the Salmonellae observed with these antigenic characters. ${ }^{9}$

\section{Clinical study of higher doses use of antibiotics in slaughter animals (Buffalo)}

There are different antibiotics are used for different purposes 
on food animals like buffalo before slaughter. These include antimicrobials, anti-inflammatories, growth promotants, parasiticides and insecticides. According to a survey of members of the American Association of Bovine Practitioners (AABP), the drugs most commonly used by practitioners for dairy cows were antibiotics, followed by antiinflammatories, tranquilizers and analgesics. Some of the antibiotics used here are Penicillin, Cephalosporine, Aminoglycosides, Streptomycin, Gentamycin, Aparamycin, Tetracycline, Erythromycin etc. Streroids and hormones are also used as growth promoters. These drug residues as per the age and use on animals, failure to absorb and regular extra level of use concern public health hazards including toxic and anaphylactic reactions and develop drug-resistant-strains of bacteria. There are different factors used to affect after slaughter. One simple factor which affects the stability of residues in tissues is the passage of time. For example, Penicillin $\mathrm{G}$ degrades after time. Another factor which will affect the viability and presence of residues in tissues are the effects of chilling and cooking. Freezing would be expected to retard degradation of chemicals. Sulfonamides were found to be stable in long-term freezing conditions. There is immense risk of these drug residues and growth promoters during consumption of food as meat and meat products causes zoonotic illness. The development of drug resistance in foodborne bacteria is another area of great concern. During a survey of antibiotics in beef and chicken in Mexico, a concurrent microbiological analysis was conducted. The predominant micro-organisms found in beef were: Staphylococcus, Enterobacter, Citrobacter, E.coli, Salmonella etc. These organisms found resistant against Penicillin, Tetracycline, Streptomycin. ${ }^{10}$

As per the Journal of "American Meat Institute" (AMI) 80\% of antibiotics used in animals, Drug residues monitored by USDA, MRSAs are common in meat and Poultry products. ${ }^{11}$

It is found that resistance of antibiotics are most serious global medical problem in $21^{\text {st }}$ century. There is evidence that resistance in some human enteric pathogens has arisen because of transfer of resistant bacteria or resistance genes from animals to people via the food chain. ${ }^{11}$ Antibiotic resistance can form in human during zoonotic transmission through following order-The first is allergic reaction and the second is development of antibiotic resistance in the gut bacteria of human. Reduction in antibiotic resistance problems in people could be assisted by improved on-farm management and farm disease control. Improvements in food production and food hygiene would reduce contamination of carcasses and meat with zoonotic food borne Salmonella, Campylobacter, E. coli and Enterococci. ${ }^{12}$

Transmission of animal to human takes place from variety of routes, food-borne route probably the most important such as Salmonella enterica, Campylobacter jejuni and Yersinia enterocolitica are the major pathogens takes part. In 1960, Salmonella in food animals and humans pass their resistance trait onto other bacteria. In 1990, detection of vancomycin-resistant Enterococcus faecium as well as quinoloneresistant Salmonella and Campylobacter in food animals and evidence of their spread to humans elevated the scientific and public concerns to new levels. A international community like WHO and OIE (World Animal Health Organisation) implemented termination on use of antimicrobial and growth promoters in Europe. ${ }^{13-15}$

The overuse of antibiotics in farm animals like buffalo, it impact in public health by food borne pathogens and form resistance against antibiotics used previously by administration of antibiotics on farm animals consume as food by human. European Union, the United
States and the World Health Organization, are agreed that drugresistant bacteria are created in farm animals by antibiotic over use. Antibiotics 2 are a precious resource in both human and veterinary medicine. They have saved countless lives since the mid-20 $20^{\text {th }}$ century. On World Health Day, 7th April 2011, the WHO Director-General, Dr Margaret Chan, warned that 'In the absence of urgent corrective and protective actions, the world is heading towards a post-antibiotic era, in which many common infections will no longer have a cure and, once again, kill unabated' and that 'The responsibility for turning this situation around is entirely in our hands'. In 1999-2001 in Europe multi-resistance food borne bacteria like Salmonella strains isolated from humans and farm animals showed high rates of antibiotic resistance in tests except for Cefotaxime ( $3^{\text {rd }}$ generation cephalosporin) and ciprofloxacin (fluoroquinolone). Multi drug resistance is higher in samples from food and farm animals and are reservoir of multi drug resistance of Salmonella. . $^{16,17}$

\section{Different sources of contamination of salmonella in slaughter house area}

Salmonellosis is described as a zoonotic infection since the major source of human illness is infected animals. Transmission is by the fecal-oral route whereby intestinal contents from an infected animal are ingested with food or water. A period of temperature abuse which allows the salmonellae to grow in the food. Salmonellae survive through cross-contamination through direct contact or indirect via contaminated equipments and contaminated handlers. Human transmission occur, if the faecally contaminated hands of an infected food handler touch during slicing or packaging. Food animals like buffalo can acquire infection in firms from wild birds and rodents or contaminated feeding stuff. Improper maintenance of hygienic condition like not using uniform, spraying of chemicals on carcass washing before enter in chillers etc. S. enteritidis increased 14-fold between 1981 and 1988, while those of S. Typhimurium less than doubled, and $S$. Enteritidis is now the commonest serotype recorded. At freezing temperature like $-42^{\circ} \mathrm{C}$ all samples of frozen buffalo meat tested and most of the samples found positive and found contaminated with Salmonella survival.

\section{Results}

In the present study 56 frozen buffalo meat samples tested, 44 samples among them found positive for Salmonella spp. All the 44 samples revealed characteristic features of Salmonella producing pink colonies with or without black centers from Xylose Lysine Deoxycholate (XLD) Agar colorless pink or pink or opaque-white colonies often surrounded by pink or red zone from Brillian Green (BG) agar or brown, gray or black colonies from Bismuth Sulphite Agar (BS) agar or blue-green to blue colonies with or without black centers from Hektoen Enteric Agar (HE) agar. On preliminary characteristic IMViC pattern Salmonella produces positive tests as per the species.

\section{Discussion}

56 frozen different cuts of buffalo meat investigated through above methodology of test. Frozen buffalo meat in slaughter house area contaminated during processing from slaughtering, carcass washing, chilling, deboning, fresh packing and till frozen condition, whereas chilling done $0-4^{\circ} \mathrm{C}$ and frozen achieved through-38 to $-42^{\circ} \mathrm{C}$. It is believed that in frozen condition Salmonella cannot 
survive. But sample tested showed they survive the frozen condition too. Salmonellae in fact, originated through different infected touch of food handlers and butchers, improper clothing, fecal hand contamination, may be through rodent and other insects or unhygienic practice in slaughter house area. They are isolated and identified by above methodological means and observed as positive for Salmonella. Hence, from the public point of view, frozen buffalo meat exported in many countries from India and human being consume the same in worldwide. There is a risk of chances for developing Salmonellosis is major due to survival of Salmonella at very low temperature too. They may come in different serotypes S. enteridis, S. typhi, S. typhimurium etc.

\section{Acknowledgements}

I am grateful to the Chancellor of Kalinga University and Principal $\&$ Ph.D Supervisor of Shivaji Science College, Chickli, Maharastra for pursuing the work on Salmonella spp.

\section{Conflict of interest}

The author declares no conflict of interest

\section{References}

1. Kshirsagar DP, Singh $\mathrm{S}$, Brahmbhatt $\mathrm{MN}$, et al. Isolation and molecular characterization of virulence-associated genes of salmonella from buffalo meat samples in western region of India. Israel Journal of Veterinary Medicine. 2014;69(4):228-233.

2. Wafaa S, Mohamed, Madeha Ibrahim A. Isolation of salmonella species from buffalo calves meat and preliminary evaluation of its irradiated vaccine. Assiut Vet Med J. 2014;16(144):18-23.

3. Galal SA, Gomaa AM, El Gohary H, et al. Screening of milk samples for Salmonella typhimurium in dairy herd using Enzyme Linked Immuno Sorbant Assay (ELISA). J Egypt Vet Med Assoc. 2008;68(3):93-105.

4. Kundu D, Gill A, Lui C, et al. Use of low dose e-beam irradiation to reduce E. coli $\mathrm{O} 157: \mathrm{H} 7$, non-O157 (VTEC) E. coli and Salmonella viability on meat surfaces. Meat Sci. 2014;96(1):413-418.
5. Martin R Adams, Maurice O Moss. Food Microbilogy. Bacterial agents of food borne illness (chapter 7). 3rd ed. 2007. p. 1-467.

6. Karaboz, Ismail, Dincer, et al. Microbiological investigation on some of the commercial frozen meat in Izmir. Turkish Electronic Journal of Biotechnology Special issue. 2002:18-23.

7. AbdElraheam Elsayed MS, Eman Abdeeen, Mohamed Ali Akiela, et al. Real time and conventional PCR for characterization of Salmonella $s p$. from imported meat to Egypt. Advances in Animal and Veterinary Sciences. 2014;2(4):199-203.

8. Wallace H Andrews, Andrew Jacobson, Thomas Hammack. BAM: Salmonella. Bacterological Analytical Mannual Chapter 5. 2011.

9. James M Jay. Foodborne gastroenteritis caused by Salmonella, Shigella and Escherichia. Modern Food Microbiology. 4th ed. Netherlands: Springer; 2005. p. 553-582.

10. Kaneene JB, Miller R. Problems associated with drug residues in beef from feeds and therapy. Rev Sci Tech. 1997;16(2):694-708.

11. Barton MD. The fact about antibiotics in livestock and poultry production. Antibiotic use in animal feed and its impact on human health. AMI (American Meat Institute); 2000. p. 1-13.

12. Chowdhury R, Haque MN, Islam KMS, et al. A Review on antibiotics in an animal feed. Bang J Anim Sci. 2009;38(1\&2):22-32.

13. WHO. Second Joint FAO/OIE/WHO workshop on non-human antimicrobial usage and antimicrobial resistance: management options. Oslo. March 15-18, 2004. Switzerland: WHO; 2004.

14. WHO. The medical impact of the use of antimicrobials in food animals: report of a WHO meeting. Berlin, Germany, 13-17, October 1997. Switzerland: WHO; 1997.

15. Henrik C Wegener. Antibiotic resistance-linking human and animal health. DTU. p. 2-39.

16. Public health and welfare. Antibiotics in farm animal production Compassion in world farming Journal. 2011.

17. Fathi A, Elnawawi, Osama A Attala, et al. Enteropathogens of public health importance in imported frozen meat and chicken. International Journal of Microbiological Research. 2012;3(1):59-63. 